\title{
Effect of Steam Treatment on the Characteristics of Oil Palm Empty Fruit Bunch and Its Biocomposite
}

\author{
Abdul Muttalib Bin Bujang and Noor Ida Amalina Binti Ahamad Nordin* \\ Faculty of Chemical and Natural Resources Engineering, Universiti Malaysia Pahang, \\ Lebuhraya Tun Razak 26300, Gambang, Pahang, Malaysia
}

\author{
* Corresponding author: \\ tel: +60162022940 \\ email:idamalina@ump.edu.my \\ Received: August 3, 2018 \\ Accepted: December 12, 2018 \\ DOI: $10.22146 /$ ijc.40906
}

\begin{abstract}
Oil palm empty fruit bunch (EFB) has a big potential in biocomposite production. The porous surface of EFB is advantageous for physical interlocking with polymer in composite fabrication. The objective of this study is to determine the properties of biocomposite prepared from steam-treated EFB with polypropylene (PP). The EFB was treated using steam at $120{ }^{\circ} \mathrm{C}$ for $30 \mathrm{~min}$ (Steam-30) and $60 \mathrm{~min}$ (Steam-60) in an autoclave. The biocomposite was prepared from EFB and PP at different fiber contents (10 and $30 \mathrm{wt} . \%)$. The Steam-30 EFB partially removed silica bodies and other impurities without damaging the surface of the EFB. The thermal stability improved from 276 to $283^{\circ} \mathrm{C}$. The Steam-30/PP biocomposite had the highest tensile strength at 10 and $30 \mathrm{wt} . \%$ $E F B$ contents with the increments of 23.9 and $23.8 \%$, respectively, compared to that of the untreated EFB/PP biocomposite. The Steam-30/PP biocomposite containing $30 \mathrm{wt} \%$ of $E F B$ had a low water absorption of 5.6\% compared to that of the untreated EFB/PP biocomposite at $7.2 \%$. In conclusion, steam treatment improved the characteristics of EFB and increased the compatibility between the fiber and polymer.
\end{abstract}

Keywords: empty fruit bunch (EFB); polypropylene (PP); biocomposite; tensile strength; water absorption

\section{- INTRODUCTION}

The production of conventional plastics is associated with carbon dioxide emission and depends on crude oil resources as the raw material. In addition, the disposal of petroleum-based plastic products is linked to environmental pollution such as polluting the rivers, lakes, and oceans [1]. The negative impacts of microplastic substances in the soil is also an emerging issue [2-3].

Therefore, biocomposites are considered to be more environmentally friendly as their products used less petroleum-based polymer and produce less toxic side products [4-5]. In palm oil mills, biomass fiber such as empty fruit bunch (EFB) is used for power generation (as a fuel for the boiler) and fertilizer in the plantation [6-7]. However, biomass fiber is not utilized efficiently due to the large amount generated on a daily basis. Therefore, there is a need to propose an alternative usage of the biomass fiber; thus it will add value to the biomass and at the same time will help in managing this biomass in the mill.

Since biomass fiber has high fiber content, it has the potential to be as reinforcement in the composite. However, to utilize EFB as a reinforcing material, there is a need to improve the characteristics of the fiber [8-9]. The incompatibility between the hydrophobic polymer and the hydrophilic fiber is the main drawback in the production of biocomposite. Steam treatment is one alternative that can be used as fiber treatment, and the treatment requires no chemical [10].

The aim of this research is to determine the properties of biocomposite prepared by steam-treated $\mathrm{EFB}$ and polypropylene (PP). The EFB underwent steam treatment at $120^{\circ} \mathrm{C}$ for 30 and 60 min that modified the fiber surface. The preparation of biocomposite involves the use of PP at different fiber contents (10 and $30 \mathrm{wt} . \%$ ). The characterization of the untreated and treated EFB was analyzed for its morphology and thermal analysis. 
As for biocomposite, tensile test, scanning electron microscopy (SEM) and water absorption analysis was conducted. Water absorption analysis able to demonstrate the toleration of biocomposite in water.

\section{- EXPERIMENTAL SECTION}

\section{Materials}

The materials used were PP, EFB, and sodium hydroxide $(\mathrm{NaOH})$. The EFB was collected from Lepar Hilir Palm Oil Mill in Gambang, Pahang. PP was bought from Commercial Plastic Industries Sdn. Bhd., Selangor, Malaysia. $\mathrm{NaOH}$ was supplied by Merck (Darmstadt, Germany) and used as received.

\section{Procedure}

\section{Fiber treatment}

The fresh EFB collected was washed and dried to remove dirt and any impurities. Steam treatment was conducted using an autoclave at $120^{\circ} \mathrm{C}$ and 21 psi for $30 \mathrm{~min}$ (Steam-30) and $60 \mathrm{~min}$ (Steam-60). For a comparison with the chemical treatment, the EFB was treated with 5 wt.\% of $\mathrm{NaOH}$ (alkali) for $3 \mathrm{~h}$ at room temperature. The untreated and treated EFB were ground and sieved to isolate ground fiber with a size of 180 $355 \mu \mathrm{m}$.

\section{Preparation of EFB/PP biocomposites}

In the production of $\mathrm{EFB} / \mathrm{PP}$ biocomposite, the materials were blended in a twin screw extruder machine (Model: Prism Eurolab 16) with fiber contents of 10 and $30 \mathrm{wt} . \%$. The extruder was operated with inlet and die temperatures of 200 and $160{ }^{\circ} \mathrm{C}$, respectively at $50 \mathrm{rpm}$ rotor speed. The blended biocomposites were pressed using hot and cold press machine (Model: Lotus Scientific-2205) with a pressure of $10 \mathrm{KPa}$ to produce thin film EFB biocomposites with a size of $10 \times 10 \mathrm{~cm}$ and $1 \mathrm{~mm}$ thick. The hot press machine was operated at $180^{\circ} \mathrm{C}$ with molding and cooling times of $10 \mathrm{~min}$ each.

\section{Thermal gravimetric analysis}

The thermal gravimetric analysis (TGA) for the EFB fiber and $\mathrm{EFB} / \mathrm{PP}$ biocomposite were done using Hitachi STA7200 thermal analysis. The analysis was conducted in a nitrogen atmosphere with a gas flow rate of $50 \mathrm{~mL} / \mathrm{min}$ by heating from 30 to $600^{\circ} \mathrm{C}$ at a heating rate of $10^{\circ} \mathrm{C} / \mathrm{min}$.
About 1-6 mg of samples were placed in an aluminum pan [11].

\section{Morphological analysis}

Hitachi TM3030 Plus tabletop microscope was used for SEM analysis. The samples were mounted on the aluminum specimen stubs using double-sided adhesive carbon tabs [11]. The SEM analysis was also done on the fractured biocomposite from tensile tests to observe the physical adhesion of EFB with the PP matrix.

\section{Tensile strength properties}

The tensile test was conducted at a crosshead speed of $10 \mathrm{~mm} / \mathrm{min}$ using an AG-1 Shimadzu universal testing machine according to ASTM D638 and fitted with a $1000 \mathrm{~N}$ load cell [12]. The average value from five specimens was taken as the tensile strength of the $\mathrm{EFB} / \mathrm{PP}$ biocomposite.

\section{Water adsorption analysis}

The weight of the samples was measured before and after the treatment. The samples were carefully cut in the size of $3 \times 2 \mathrm{~cm}$ to avoid any cracks. The specimens were dried at $60^{\circ} \mathrm{C}$ in an oven until a constant weight was reached. The initial weight of the dried samples was recorded. The samples were immersed in distilled water for 12 days at room temperature, and the weight increment was recorded [13].

\section{- RESULTS AND DISCUSSION}

\section{Thermal Stability Analysis of EFB}

The thermal degradation of EFB analyzed by TGA is shown in Table 1 by indicating the weight loss of the sample at 5, 20, and 50\% weight loss. Also included is the percentage of residual of EFB at $550{ }^{\circ} \mathrm{C}$. Fig. 1 shows the weight loss of the EFB sample, and three regions are denoting the weight loss: (i) $<100{ }^{\circ} \mathrm{C}$, (ii) $150-220^{\circ} \mathrm{C}$, and (iii) $240-350{ }^{\circ} \mathrm{C}$. The weight loss at less than $100^{\circ} \mathrm{C}$ was due to moisture content. The second region of weight loss may be due to the hemicellulose component. It was reported that hemicellulose is enriched with carbon sugars chain and branched structures, which are susceptible to decomposition at low temperature (200$260{ }^{\circ} \mathrm{C}$ ) [14]. The third region of weight loss is contributed to cellulose degradation. The residual mass 
Table 1. Thermal stability analysis for EFB

\begin{tabular}{lcccc}
\hline EFB sample & $\begin{array}{c}\text { Temperature for } 5 \% \\
\text { weight loss }\left({ }^{\circ} \mathrm{C}\right)\end{array}$ & $\begin{array}{c}\text { Temperature for } 20 \% \\
\text { weight loss }\left({ }^{\circ} \mathrm{C}\right)\end{array}$ & $\begin{array}{c}\text { Temperature for } 50 \% \\
\text { weight loss }\left({ }^{\circ} \mathrm{C}\right)\end{array}$ & $\begin{array}{c}\text { Residue at } 550{ }^{\circ} \mathrm{C} \\
(\%)\end{array}$ \\
\hline Untreated & 54.22 & 276.53 & 326.29 & 24.33 \\
Steam-30 & 66.37 & 283.26 & 328.27 & 25.13 \\
Steam-60 & 55.09 & 279.93 & 327.34 & 24.70 \\
Alkali & 69.13 & 293.66 & 336.93 & 27.11 \\
\hline
\end{tabular}

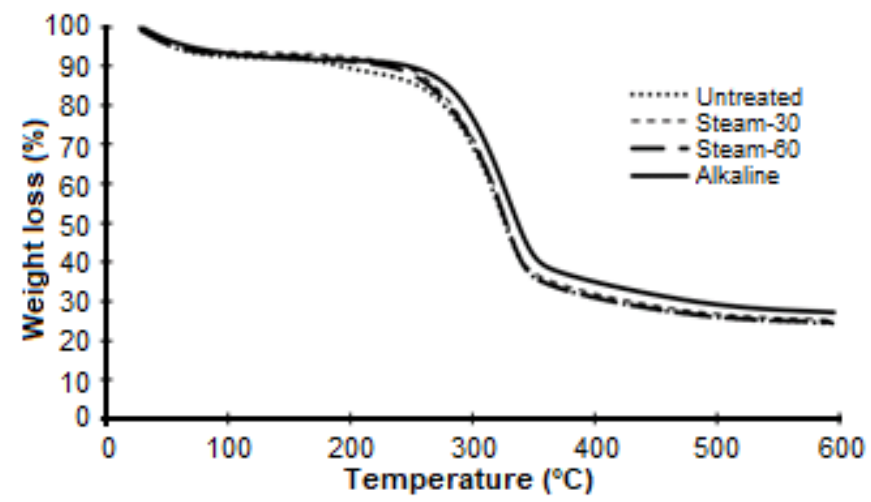

Fig 1. TG analysis for untreated and treated EFB

left at $550{ }^{\circ} \mathrm{C}$ mainly containing lignin [13].

In overall, the thermal degradation of treated $\mathrm{EFB}$ was increased compared to untreated EFB. The thermal degradation of the untreated $\mathrm{EFB}$ was recorded at a lower temperature compared to the treated $\mathrm{EFB}$ due to the presence of thermally unstable components such as hemicelluloses and low molecular lignin [15].

From Fig. 1, it can be observed that the weight loss in the temperature range of $150-220{ }^{\circ} \mathrm{C}$ contributes to hemicellulose content in the untreated EFB. While the partial removal of hemicelluloses after steam and alkali treatment increased the thermal degradation of the fiber [14]. Residue for treated samples was higher compared to the untreated fiber show that the treated fiber had a higher percentage of lignin. Lignin contains non-polar hydrocarbon and benzene rings making it less hydrophilic. Thus, the increased residue shows the treated fiber had better hydrophobicity compared to untreated fiber.

\section{Morphological Analysis of EFB}

Fig. 2 shows the images of EFB at $300 \times, 500 \times$, and $1000 \times$ magnifications. The untreated EFB surfaces were covered with silica bodies. However, the silica bodies are not clearly observed due to wax and other impurities that covered the surface of the fiber. Silica bodies in nature act as a shield against fungal attack and give support to the plant structure [13]. Fig. 2(b) shows the structure of Steam-30 where it can be observed that the silica bodies were partially removed making the strand to have a rough surface. The removal of silica on fiber surface is good for fiber-matrix adhesion because it provides the physical interlocking between the fiber and polymer [11].

Fig. 2(c) shows a rough surface of Steam-60 compared to Steam-30 due to the longer retention time exposed to the high pressure of steam. More silica bodies were removed from the surfaces, and the fiber surfaces were cracked and damaged. The open structure of the fiber due to crack will benefit the adhesion between fiber and polymer, where the polymer can penetrate the
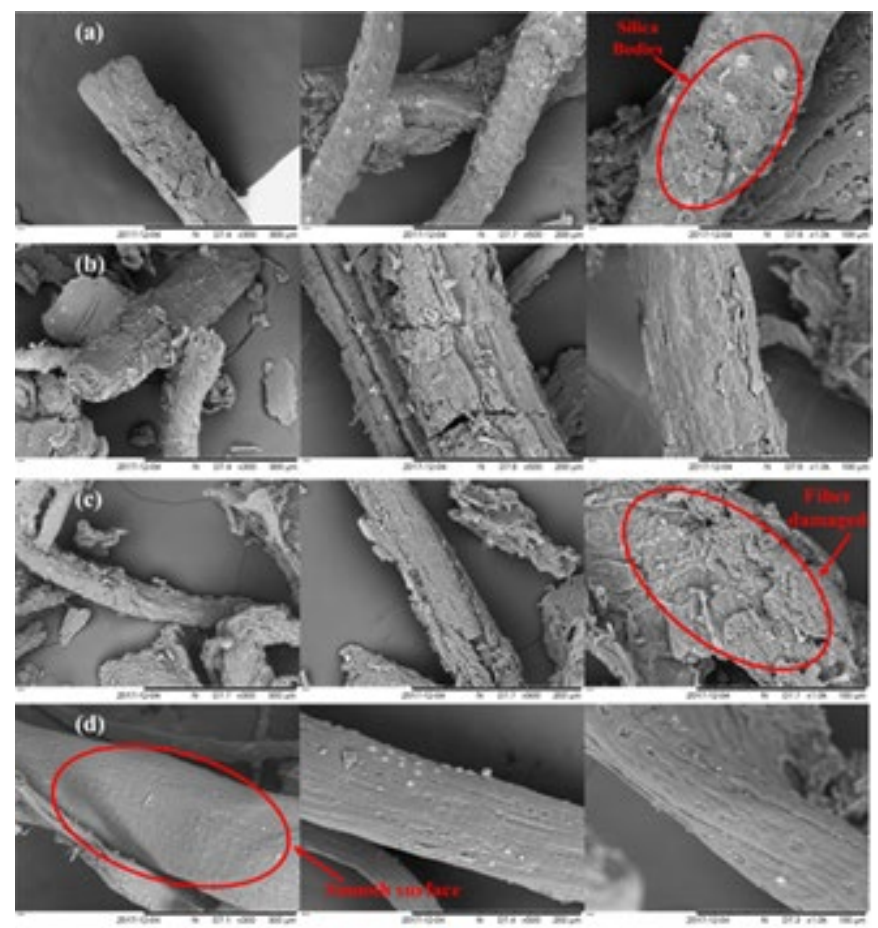

Fig 2. Morphology analyses of EFB, (a) Untreated, (b) Steam-30, (c) Steam-60, and (d) Alkali 
structure of the fiber; thus adhesion is improved. Fig. 2(d) shows that the structure of Alkali treated EFB changed. According to Izani et al. [11], $\mathrm{NaOH}$ treatment removes the wax and cuticle by the interaction with sodium and makes the surfaces of EFB smoother [16].

\section{Tensile Properties of EFB/PP Biocomposites}

Table 2 shows the data for the tensile strength of $\mathrm{EFB} / \mathrm{PP}$ biocomposites from different treatments and percentages of EFB loading. The tensile strength decreased as the percentage of EFB loading was increased. Steam-30 biocomposite had the highest tensile strengths for both 10 and $30 \mathrm{wt} . \%$ of EFB loadings followed by Alkali, untreated, and Steam-60 biocomposite.

It was reported that the tensile strength for pure PP was around 30-40 MPa [17]. Biocomposite prepared from $10 \mathrm{wt} . \%$ of EFB loading was able to improve the tensile strength of PP in the range of 43-60\%. Meanwhile, $30 \mathrm{wt} . \%$ of EFB loading improved the tensile strength for 30-44\%.

\section{Thermal Stability Analysis of EFB/PP Biocomposites}

Table 3 shows the thermal stability of the EFB/PP biocomposite. In overall, the thermal stability of biocomposites prepared from treated EFB had improved compared to untreated EFB biocomposite. Fig. 3 presents the weight loss of the untreated EFB and treated EFB/PP biocomposites at $30 \mathrm{wt} . \%$ of EFB loading.

The first stage of thermal degradation of $\mathrm{EFB} / \mathrm{PP}$ biocomposite started at a temperature above $270{ }^{\circ} \mathrm{C}$ due to the fiber content in the polymer matrix. The second stage started to degrade at a temperature of $410^{\circ} \mathrm{C}$ was due to the PP.

\section{Morphological Analysis of EFB/PP Biocomposites}

Fig. 4 shows the SEM images of the fractured sample from a tensile test of the EFB/PP biocomposites at 30 wt.\% fiber loading.
Fig. 4(a) shows that the fiber was pulled out indicating a poor adhesion between the fibers and

Table 2. Tensile strengths of EFB/PP biocomposites

\begin{tabular}{lcc}
\hline \multirow{2}{*}{$\begin{array}{l}\text { EFB/PP } \\
\text { biocomposite }\end{array}$} & $\begin{array}{c}\text { Tensile strength }(\mathrm{MPa}) \\
\text { 10 wt.\% of EFB } \\
\text { loading }\end{array}$ & $\begin{array}{c}30 \mathrm{wt} \% \text { of EFB } \\
\text { loading }\end{array}$ \\
\hline Untreated & 72.22 & 51.70 \\
Steam-30 & 89.45 & 64.00 \\
Steam-60 & 62.21 & 50.91 \\
Alkali & 76.53 & 54.24 \\
\hline
\end{tabular}

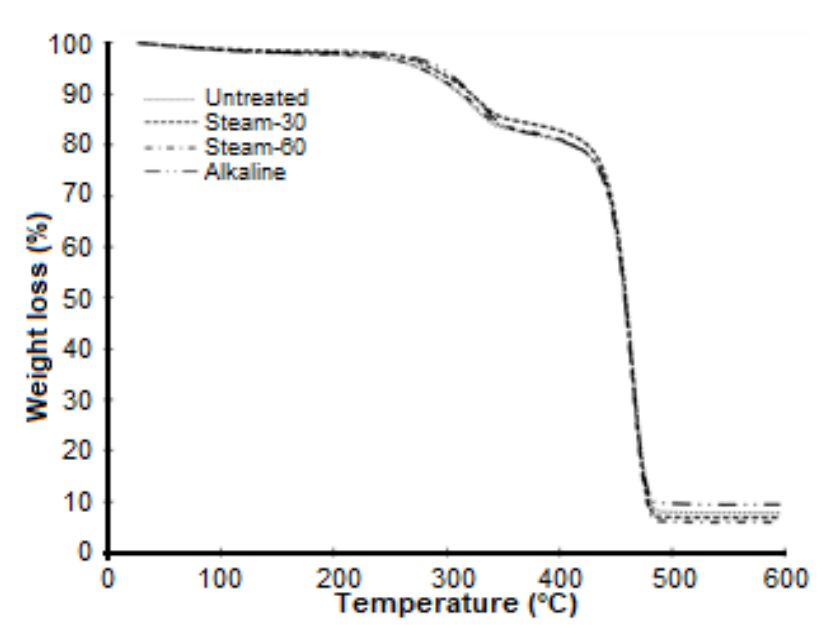

Fig 3. TG analysis of EFB/PP biocomposites

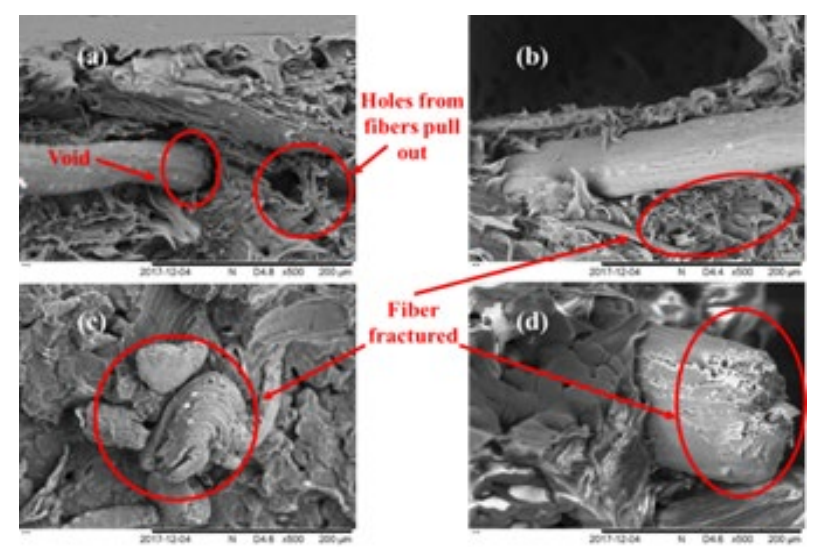

Fig 4. Morphology analysis of EFB/PP biocomposite: (a) Untreated, (b) Steam-30, (c) Steam-60, and (d) Alkali

Table 3. Thermal stability analysis of EFB/PP biocomposite with 30 wt.\% fiber loading

\begin{tabular}{lcccc}
\hline $\begin{array}{l}\text { EFB/PP } \\
\text { biocomposites }\end{array}$ & $\begin{array}{c}\text { Temperature for } \\
5 \% \text { weight loss }\left({ }^{\circ} \mathrm{C}\right)\end{array}$ & $\begin{array}{c}\text { Temperature for } \\
\text { 20\% weight loss }\left({ }^{\circ} \mathrm{C}\right)\end{array}$ & $\begin{array}{c}\text { Temperature for } \\
50 \% \text { weight loss }\left({ }^{\circ} \mathrm{C}\right)\end{array}$ & $\begin{array}{c}\text { Residue at } 550{ }^{\circ} \mathrm{C} \\
(\%)\end{array}$ \\
\hline Untreated & 277.58 & 411.77 & 459.70 & 7.70 \\
Steam-30 & 287.67 & 425.02 & 459.03 & 6.74 \\
Steam-60 & 277.77 & 413.38 & 458.14 & 5.87 \\
Alkali & 295.29 & 410.95 & 458.22 & 9.38 \\
\hline
\end{tabular}


matrix [18]. However, the treated EFB biocomposites have a better adhesion between fiber and PP matrix where fiber breakage can be observed. The fibers were well wetted by the PP matrix, and fiber breakages occurred due to strong adhesion.

According to Kabir et al. [19], better mechanical properties of composites can be achieved after modifying the surface of the natural fiber. The images were in agreement with results obtained from the tensile test.

\section{Water Absorption Analysis of EFB/PP Biocomposite}

Table 4 shows the maximum water absorption for the untreated and Steam-30 biocomposite was 7.16 and $5.59 \%$, respectively.

Nadzri et al. [20] reported that the untreated fiber exhibited the highest water absorption that attributed the existed of void or gap between fiber and PP. The presence of a void in biocomposite structure makes it absorbs more water. Water absorption analysis for EFB/PP biocomposite was illustrated in Fig. 5.

Both biocomposite samples absorbed water after immersed in water until reaching the saturation point. The untreated EFB/PP biocomposite absorb 22\% more water than Steam-30 biocomposite. Steam-30 biocomposite had

Table 4. Water absorption of untreated and Steam-30 biocomposite

\begin{tabular}{lc}
\hline $\begin{array}{c}\text { EFB/PP biocomposite } \\
\text { sample }\end{array}$ & $\begin{array}{c}\text { Maximum water } \\
\text { absorption (\%) }\end{array}$ \\
\hline Untreated & 7.16 \\
Steam-30 & 5.59 \\
\hline
\end{tabular}

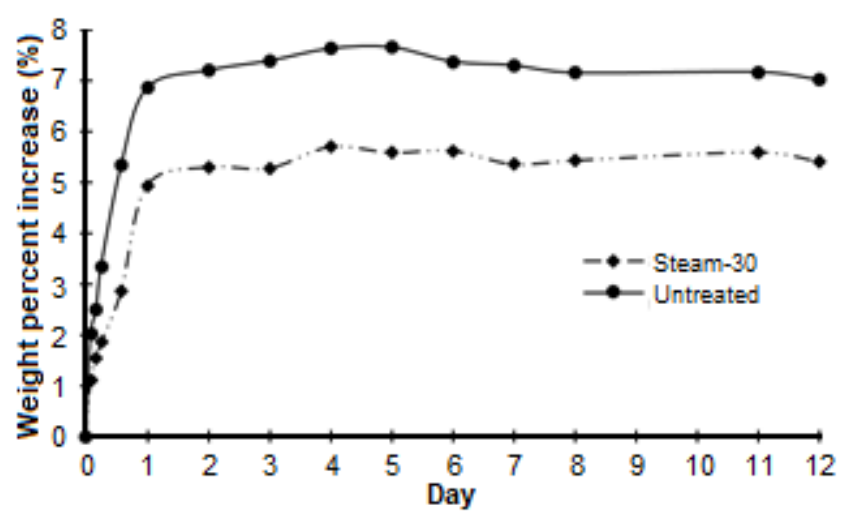

Fig 5. Water absorption of untreated and Steam-30 biocomposite with $30 \mathrm{wt} . \%$ EFB loading low water absorption due to the removal of hemicellulose which makes the fiber less hydrophilic. Water will be absorbed by the hydroxyl groups contained in the hemicellulose which tends to make a hydrogen bond with water molecules that will increase the absorption of water [12]. Eliminating hydrophilic hydroxyl groups from the fiber structure through fiber treatments able to lower the water absorption of fiber [19]. In this study, steam treatment for 30 min was able to partially remove hemicellulose content in the EFB that directly decreased the water absorption of its EFB/PP biocomposite.

\section{- CONCLUSION}

The thermal stability, morphological, water absorption, and mechanical properties of the EFB/PP biocomposites were studied in this research. The tensile properties of the EFB/PP biocomposites improved after steam treatment for $30 \mathrm{~min}$. However, the tensile strength decreased gradually with respect to the increased EFB loading. Meanwhile, the retention time of the steam treatment is very important to avoid the surface of the EFB fiber from damage and cracks where it will reduce the mechanical properties of the biocomposite. The steam treatment for $30 \mathrm{~min}$ showed the best performance in terms of thermal stability, morphological, mechanical properties, and water absorption. The thermal stability of Steam-30 increased from 276 to $283{ }^{\circ} \mathrm{C}$. The treated fiber had a rough surface, low silica bodies, and presence of crater (due to the removal of silica) which will benefit for polymer adhesion. The tensile strength of Steam 30 with $30 \mathrm{wt} . \%$ of fiber content increased almost double compared to that of the pure PP composites. It also had low water absorption which was $22 \%$ lower than the untreated EFB biocomposite. In conclusion, steam treatment was able to treat the EFB fiber for better adhesion of the natural fiber EFB with the PP polymer matrix.

\section{- ACKNOWLEDGMENTS}

The authors acknowledge Universiti Malaysia Pahang for financial support through grant number RDU1703177. 


\section{- REFERENCES}

[1] Akindoyo, J.O., Beg, M.D., Ghazali, S., Islam, M.R., and Mamun, A.A., 2015, Preparation and characterization of poly(lactic acid)-based composites reinforced with poly dimethyl siloxane/ultrasoundtreated oil palm empty fruit bunch, Polym. Plast. Technol. Eng., 54 (13), 1321-1333.

[2] Scherer, C., Emberger-Klein, A., and Menrad, K., 2017, Biogenic product alternatives for children: Consumer preferences for a set of sand toys made of bio-based plastic, Sustainable Prod. Consumption, $10,1-14$.

[3] Palamae, S., Dechatiwongse, P., Choorit, W., Chisti, Y., and Prasertsan, P., 2017, Cellulose and hemicellulose recovery from oil palm empty fruit bunch (EFB) fibers and production of sugars from the fibers, Carbohydr. Polym., 155, 491-497.

[4] Brockhaus, S., Petersen, M., and Kersten, W., 2016, A crossroads for bioplastics: exploring product developers' challenges to move beyond petroleumbased plastics, J. Cleaner Prod., 127, 84-95.

[5] Sanjay, M., Arpitha, G., Naik, L., Gopalakrishna, K., and Yogesha, B., 2016, Applications of natural fibers and its composites: An overview, Nat. Resour., 7, 108-114.

[6] Shamsudin, S., Shah, U.K.M., Zainudin, H., AbdAziz, S., Kamal, S.M.M., Shirai, Y., and Hassan, M.A., 2012, Effect of steam pretreatment on oil palm empty fruit bunch for the production of sugars, Biomass Bioenergy, 36, 280-288.

[7] Awalludin, M.F., Sulaiman, O., Hashim, R., and Nadhari, W.N.A.W., 2015, An overview of the oil palm industry in Malaysia and its waste utilization through thermochemical conversion, specifically via liquefaction, Renewable Sustainable Energy Rev., 50, 1469-1484.

[8] Dhandapani, S., Nayak, S., and Mohanty, S., 2015, Surface modification of oil palm fruit bunch and fibre reinforcement effect on bio-based polyester matrix composites: Dynamic, morphology, thermal and mechanical properties, J. Elastomers Plast., 48 (5), 456-479.
[9] Hosseinaei, O., Wang, S., Enayati, A.A., and Rials, T.G., 2012, Effects of hemicellulose extraction on properties of wood flour and wood-plastic composites, Composites Part A, 43 (4), 686-694.

[10] Nordin, N.I.A.A., Ariffin, H., Andou, Y., Hassan, M.A., Shirai, Y., Nishida, H., Yunus, W.M.Z.W., Karuppuchamy, S., and Ibrahim, N.A., 2013, Modification of oil palm mesocarp fiber characteristics using superheated steam treatment, Molecules, 18 (8), 9132-9146.

[11] Izani, M.A.N., Paridah, M.T., Anwar, U.M.K., Nor, M.Y.M., and H'Ng, P.S., 2013, Effects of fiber treatment on morphology, tensile and thermogravimetric analysis of oil palm empty fruit bunches fibers, Composites Part B, 45 (1), 12511257.

[12] Beg, M.D.H., Akindoyo, J.O., Ghazali, S., and Mamun, A.A., 2015, Impact modified oil palm empty fruit bunch fiber/poly (lactic) acid composite, Int. J. Chem. Nucl. Mater. Metall. Eng., $9(1), 165-170$.

[13] Abdullah, M.A., Nazir, M.S., Raza, M.R., Wahjoedi, B.A., and Yussof, A.W., 2016, Autoclave and ultrasonication treatments of oil palm empty fruit bunch fibers for cellulose extraction and its polypropylene composite properties, J. Cleaner Prod., 126, 686697.

[14] Harun, N.A.F., Baharuddin, A.S., Zainudin, M.H.M., Bahrin, E.K., Naim, M.N., and Zakaria, R., 2013, Cellulase production from treated oil palm empty fruit bunch degradation by locally isolated Thermobifida fusca, BioResources, 8 (1), 676-687.

[15] Shinoj, S., Visvanathan, R., Panigrahi, S., and Kochubabu, M., 2011, Oil palm fiber (OPF) and its composites: A review, Ind. Crops Prod., 33 (1), 722.

[16] Zailuddin, N.L.I., and Husseinsyah, S., 2016, Tensile properties and morphology of oil palm empty fruit bunch regenerated cellulose biocomposite films, Procedia Chem., 19, 366-372.

[17] Rayung, M., Ibrahim, N., Zainuddin, N., Saad, W., Razak, N., and Chieng, B.W., 2014, The effect of 
fiber bleaching treatment on the properties of poly(lactic acid)/oil palm empty fruit bunch fiber composites, Int. J. Mol. Sci., 15 (8), 14728-14742.

[18] Jacob, M., Thomas, S., and Varughese, K.T., 2004, Mechanical properties of sisal/oil palm hybrid fiber reinforced natural rubber composites, Compos. Sci. Technol., 64 (7-8), 955-965.

[19] Kabir, M.M., Wang, H., Lau, K.T., and Cardona, F.,
2012, Chemical treatments on plant-based natural fibre reinforced polymer composites: An overview, Composites Part B, 43 (7), 2883-2892.

[20] Nadzri, N.I.M., Jamaludin, S.B., and Noor, M.M., 2012, Development and properties of coconut fiber reinforced composite cement with the addition of fly ash, J. Sustainable Cem.-Based Mater., 1 (4), 186-191. 